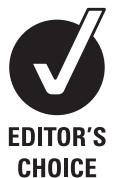

See Editorial Commentary, p 707

${ }^{1}$ Assistance Publique Hôpitaux de Marseille, Hôpital de la Timone, Service de Neurophysiologie Clinique, Marseille, France

${ }^{2}$ Aix Marseille Université, Faculté de Médecine, Marseille, France

${ }^{3}$ Assistance Publique Hôpitaux de Marseille, Hôpital de la Timone, Service de Médecine Nucléaire, Marseille, France ${ }^{4}$ Centre de Recherche en Automatique de Nancy (CRAN), Nancy, France

${ }^{5}$ Nancy Université, Nancy Brabois, Nancy, France

\section{Correspondence to}

Dr Martine Gavaret, Service de Neurophysiologie Clinique, Hôpital de la Timone, 264 rue Saint Pierre,

Marseille 13005, France martine.gavaret@ap-hm.fr

Received 20 February 2009 Revised 19 May 2009 Accepted 4 June 2009

\title{
Reading epilepsy from the dominant temporo-occipital region
}

Martine Gavaret, ${ }^{1,2}$ Eric Guedj, 2,3 Laurent Koessler, ${ }^{4,5}$ Agnès Trébuchon-Da Fonseca, 1,2 Sandrine Aubert, ${ }^{1,2}$ Olivier Mundler, ${ }^{2,3}$ Patrick Chauvel, ${ }^{1,2}$ Fabrice Bartolomei ${ }^{1,2}$

\section{ABSTRACT}

Background Reading epilepsy is a rare form of epilepsy, classified among idiopathic, age- and localisation-related (partial) epilepsies as a reflex epilepsy syndrome. Seizures usually consist of myoclonic jerks restricted to the jaw. However, distinct ictal features including visual symptoms and paroxysmal a- or dyslexia are described in some patients. The anatomical substrate of ictogenesis in reading epilepsy remains poorly understood.

Methods The authors report here the case of a primary reading epilepsy for which ictal semiology was characterised by visual symptoms and dyslexia, investigated by $\mathrm{MRI}$, interictal high-resolution EEG and PET, ictal video-EEG and SPECT. Brain MRI was normal. Interictal high-resolution EEG was performed with 64 scalp channels, a realistic head model and different algorithms to solve the inverse problem.

Results Interictal source localisations highlighted the left occipito-temporal junction. Interictal PET demonstrated bilateral occipito-temporal hypometabolism with leftsided predominance. Ictal EEG showed a rhythmic discharge in left temporo-parieto-occipital junction channels, with left occipito-temporal predominance. MRI fusion of the coregistered subtraction between ictal and interictal SPECT individualised relative hyperperfusion affecting (a) the left occipito-parietal junction area, (b) the left lateral middle and inferior temporal gyri and (c) the left inferior frontal area.

Conclusion Besides reading-induced myoclonic jerks of the jaw, a second variant of reading epilepsy exists with clearly partial seizures manifested by visual symptoms and a- or dyslexia. These seizures originate from the occipito-temporal region of the dominant hemisphere, corresponding to the posterior part of the neural network that underlies the function of reading.

\section{INTRODUCTION}

Reading epilepsy is a rare syndrome, a distinct form of reflex epilepsy in which all, or almost all, seizures are precipitated by the act of reading. ${ }^{1}$ Reading epilepsy was first described by Bickford et al, ${ }^{2}$ who initially distinguished between 'primary' and 'secondary' reading epilepsy. In 'primary' reading epilepsy, seizures occurred only in relation to reading, whereas patients with 'secondary' reading epilepsy had seizures under other conditions, too. However, this original dichotomous classification remained controversial. Reflex seizures or cortical myoclonus triggered by language activities have been described in patients with distinct cerebral pathologies. $^{3-5}$ Some authors thus indicated that a revision of this classification is needed, based on an accurate and detailed database. ${ }^{6}$
Primary reading epilepsy is classified in the 1989 ILAE classification among idiopathic, age- and localisation-related (partial) epilepsies as a reflex epilepsy syndrome. ${ }^{7}$ In this syndrome, seizures characteristically consist of reading-induced myoclonic jerks of the jaw or throat which may progress to generalised seizure activity. ${ }^{1} 2$ 8 However, many other types of ictal symptoms have been described ${ }^{6}$ : abrupt loss of consciousness, ${ }^{9}$ absences, ${ }^{10}$ paroxysmal a- or dyslexia ${ }^{11}$ and visual symptoms. $^{6} 8 \quad 12-17$ Visual system abnormalities appear to be important in the generation of seizures in at least some reading epilepsy patients. ${ }^{6}$

Reading is a complex cognitive process including visual analysis, memory functions, grapheme-tophoneme conversion, more or less followed by articulation and acoustic monitoring. ${ }^{18}$ Variable cortical hyperexcitability may explain the variable distribution of epileptic discharges in reading epilepsy. Some cases of reading epilepsy are related to posterior epilepsies with particular implication of the left temporo-parieto-occipital junction. ${ }^{1} 681213161719$

The anatomical basis of reading epilepsy remains poorly understood. ${ }^{18} 20$ We report here a case of reading epilepsy for which ictal semiology and noninvasive studies (high-resolution EEG, PET, ictal video-EEG recording, ictal SPECT) strongly argued for a left occipito-temporal origin of the pathological process.

\section{CLINICAL HISTORY}

A 31-year-old right-handed woman presented partial seizures that always occurred during silent reading. Seizures began at the age of 28 years. During the 3 years prior to assessment, she had experienced a total of eight seizures. Her medical history was marked by a single, apparently uncomplicated febrile seizure at the age of 4 . She had a family history of epilepsy with one grandfather having presented tonic-clonic seizures and the other grandfather having had seizures evocative of a temporal origin. Physical and neurological examinations were normal.

Seizures began during silent reading with the feeling of no longer being able to understand what she was reading (a- or dyslexia). After looking up from the page, she then continued to see letters and words despite actual disappearance of that image from either visual field (palinopsia). She had a feeling of strangeness. She could then have right hemi-body jerks and secondary generalisation. Seizures usually occurred soon after the onset of reading (less than $10 \mathrm{~min}$ ). All seizures occurred during silent reading. She had not abandoned 


\section{A, B, C : Surface EEG}
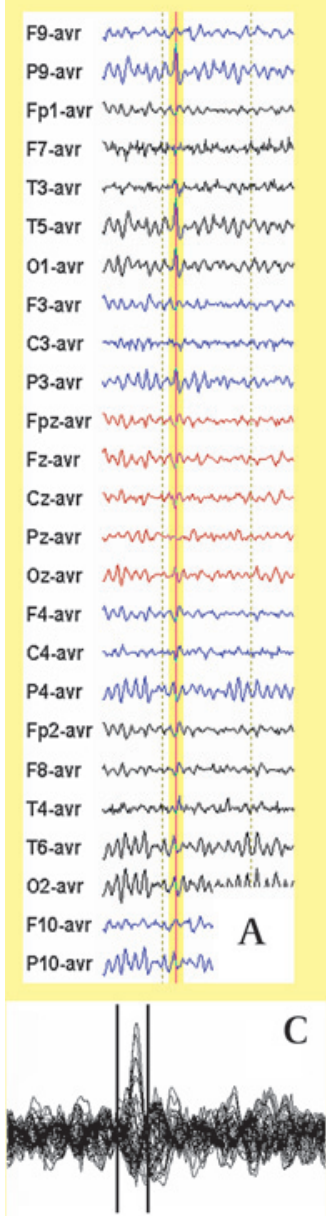
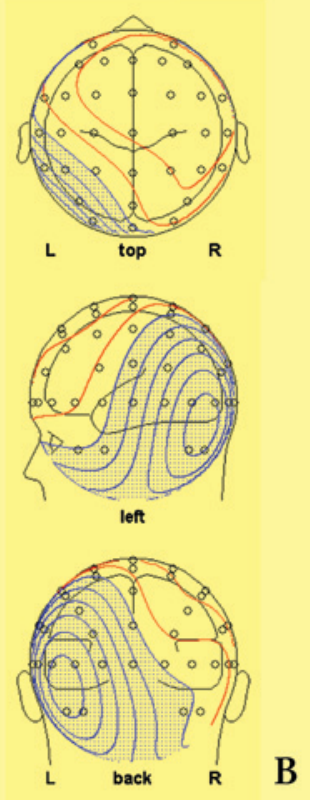

Voltage [ $16 \mu \mathrm{V} /$ line ]

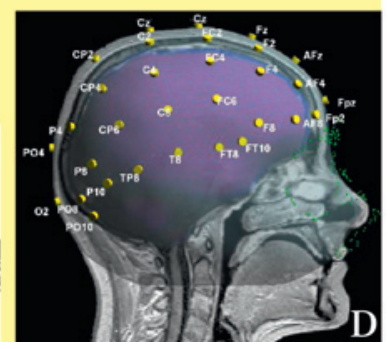

E: Source localizations

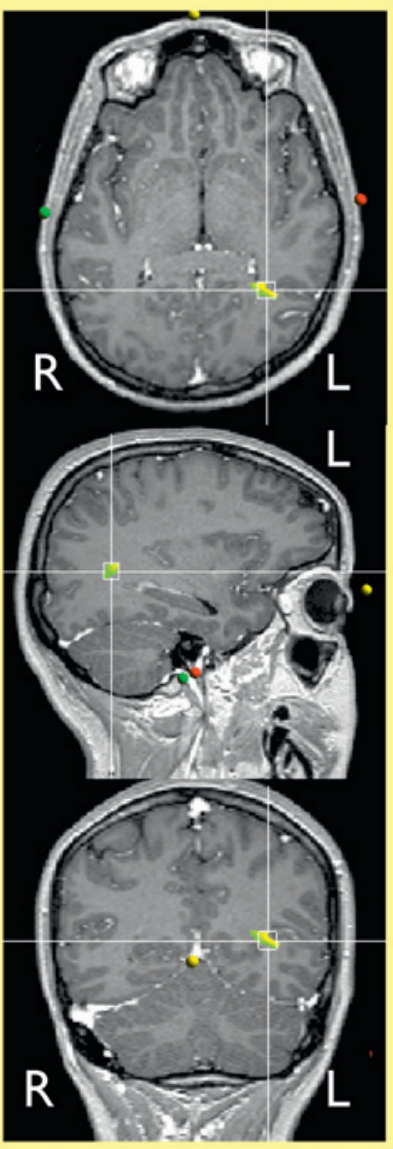

Equivalent current dipole

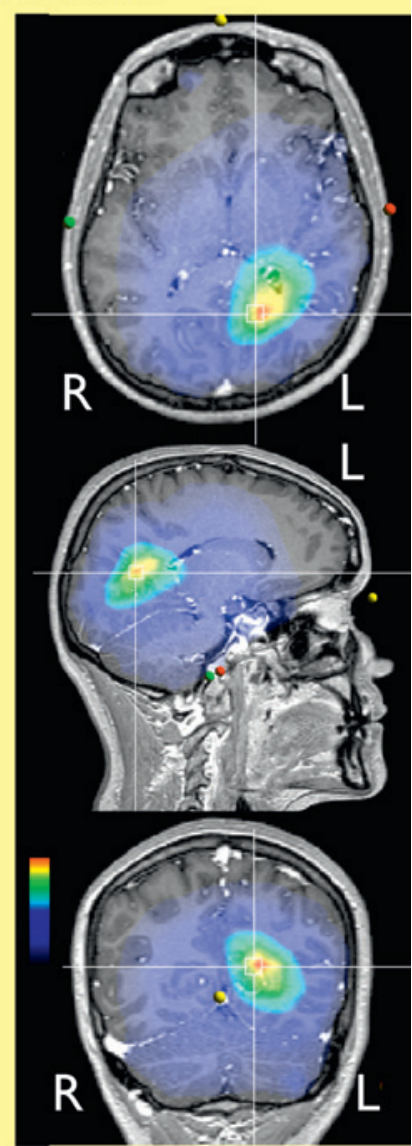

MUSIC

Figure 1 High-resolution EEG, performed with 64 scalp-channels, a high sampling rate $(1000 \mathrm{~Hz})$, a realistic head model and different source localization algorithms such as equivalent current dipoles and multiple signal classification. (A) Some isolated interictal spikes were recorded. Their amplitude was maximal on channels P03, P07, P9, T5 and 01. (B) Amplitude cartography (using Focus software) during the single interictal spike marked by the vertical line in panel A. (C) 64 channels superimposed, temporal window of analysis lying between the vertical lines. (D) Realistic head model performed with the patient's 3D MRI. Electrode positions are represented in the same spatial reference. (E) Interictal source localisations, either with an equivalent current dipole (moving dipole, goodness of fit 0.87) or with Multiple Signal Classification, indicating the left occipito-temporal junction.

reading altogether but had developed a distinct style of reading to try to avoid the onset of seizures, in that she read only for short periods and tended to scan the page diagonally. She was initially treated by lamotrigine $(200 \mathrm{mg} /$ day $)$ but seizures persisted with secondary generalisation. Replacement of lamotrigine with carbamazepine $(1000 \mathrm{mg} /$ day) led to a considerable improvement.

\section{NON-INVASIVE INVESTIGATIONS}

Neuropsychological examination was normal without discrepancies between verbal and visuo-spatial performances. Interictal EEG (24 scalp-EEG channels: 10/20 system with four additional baso-temporal channels) showed isolated left temporal posterior spikes with an inversion of polarity on left temporal posterior channel T5. With a monopolar montage and an average reference, spikes were of maximal amplitude on channels T5, TP9, T3 and FT9. There was no photoparoxysmal response.

High-resolution EEG (HR-EEG) was performed with 64 scalpchannels, a high sampling rate $(1000 \mathrm{~Hz})$, a realistic head model and different source localisation algorithms such as equivalent current dipoles $^{21}$ and MUSIC (Multiple Signal Classification, as described by Mosher et $a^{22}$ ). Detailed methodology has been previously described. ${ }^{23}$ Informed consent was obtained from the patient, and the HR-EEG study was approved by the institutional review board of the French Institute of Heath (IRB0000388, FWA00005831). Some isolated interictal spikes were recorded. These were of maximal amplitude on left temporo-parieto-occipital junction channels PO3, PO7, P9, T5 and 01 . Interictal source localisations, either with an equivalent current dipole or with MUSIC, indicated the left occipitotemporal junction (figure 1).

Brain MRI was normal. Interictal $\left[{ }^{18} \mathrm{~F}\right]$ fluorodeoxyglucosePET showed bilateral occipito-temporal hypometabolism with left-sided predominance (figure 2).

During video-EEG monitoring, a seizure was recorded $5 \mathrm{~min}$ after silent reading of a women's magazine. Clinically, the patient experienced habitual subjective signs (a- or dyslexia, palinopsia). She stopped reading at the beginning of the seizure and signalled to the nurses. She was able to explain that a seizure had started and presented a vocalisation, eyes and head deviation to the right and then right-hemi-body jerks followed by secondary generalisation. Ictal EEG showed a rhythmic 
Figure 2 Interictal $\left[{ }^{18} \mathrm{~F}\right]$ fluorodeoxyglucose-PET axial slices showing a bilateral occipito-temporal hypometabolism with a left predominance.

\section{Interictal PET}

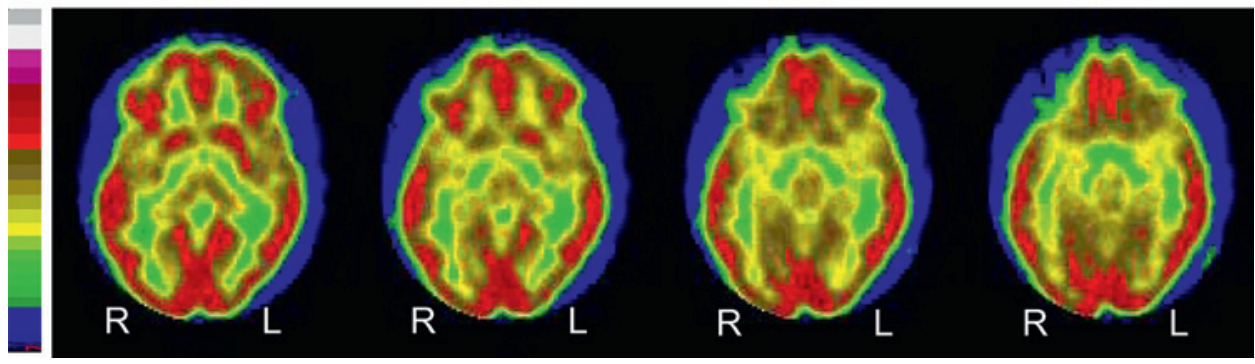

discharge in left temporo-parieto-occipital junction channels, with a left occipito-temporal predominance (figure 3).

Injection of $99 \mathrm{mTc}-\mathrm{ECD}$ for ictal SPECT was performed $30 \mathrm{~s}$ after the beginning of the seizure. Subtraction between ictal and interictal SPECT was performed. The MRI fusion of the coregistered SPECT subtraction individualised relative hyperperfusion affecting several regions including (a) the left occipito-parietal junction area, (b) the left lateral temporal region (including middle and inferior temporal gyri) and (c) the left inferior frontal area (figure 4).

\section{DISCUSSION}

The clinical picture and investigations were suggestive of involvement of dominant temporo-occipital region. Reading epilepsy is an uncommon type of reflex epilepsy. ${ }^{24}$ In the literature, a few reading epilepsy cases were characterised by visual symptoms, paroxysmal a- or dyslexia or a combination of both, suggestive of left posterior cortex involvement (one case in Chavany et al, ${ }^{12}$ one case in Bingel, ${ }^{13}$ one case in de Weerdt and Van Rijn, ${ }^{16}$ one case in Gastaut and Tassinari, ${ }^{19}$ two cases in Koutroumanidis et al, ${ }^{1} 19 / 111$ cases in the metanalysis by Wolf and Inoué $^{17}$ ). Visual symptoms could consist of elementary visual hallucinations, 'sensation of spots before the eyes, blurred vision,' as described in 1957 for one case, experiencing seizures only after prolonged reading or playing cards. ${ }^{13}$ Visual illusions, with an impression of movement and palinopsia (persistent perception despite disappearance of the stimulus) were also described and appeared to be linked to dyslexia. ${ }^{12} 1619$ Thus, in 1956, the case of a 30-year-old patient was described with ictal semiology characterised by the impression that letters had changed place, animated by vertical and horizontal movements, rendering words incomprehensible. ${ }^{12}$ All seizures occurred during reading. These subjective signs were followed by right hemi-body jerks and generalisation. ${ }^{12}$ In another publication, very similar ictal semiology was described. ${ }^{19}$ Indeed, a later case from 1966 was thus described: 'at the onset, the patient saw the last word in a foggy way, then this word becomes fixed before him even though he keeps his eyes closed; then the letters change place and the word becomes distorted. ${ }^{, 19}$ In another publication, ictal visual signs were followed by jaw jerks, with this description of a single case published in 1975: 'after reading for some time, the letters started dancing before her eyes; the sensation was followed shortly afterwards by muscular spasms of the jaw, mouth and tongue. ${ }^{16}$ Two patients have been described as having reading-provoked paroxysmal a- or dyslexia ${ }^{1}$ combined with left temporal EEG rhythmical activities. Previous
Figure 3 Ictal EEG. A seizure was recorded in the EEG video after 5 min of silent reading of a women's magazine. Clinically: (1) patient stopped reading and alerted nurses about the beginning of the seizure, (2) 'It's alright but I feel....,' (3) injection for the ictal SPECT, $30 \mathrm{~s}$ after the beginning of the seizure, (4) elementary vocalisation 'eh . oh...,' (5) respiration became deeper, (6) 'I always have the same one as that,' (7) eye deviation to the right, (8) elementary vocalisation 'eh....,' (9) eye and head deviation to the right, (10) loss of contact, (11) right brachio-facial jerks, (12) tonic-clonic generalisation. Ictal EEG showed initially a rhythmic discharge in left temporo-parietooccipital junction channels, with a left occipito-temporal predominance (surrounded).

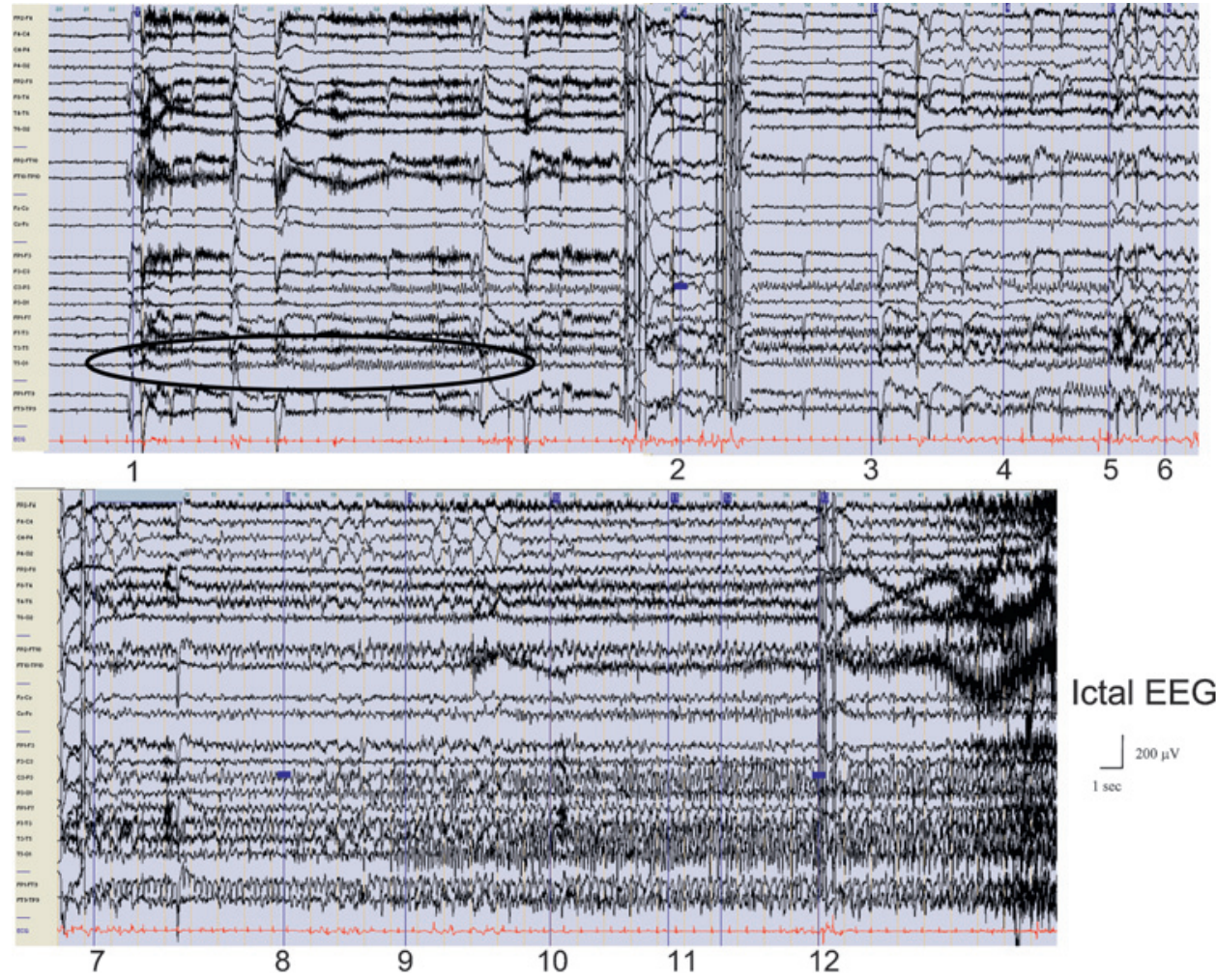


Figure $4 \mathrm{MRI}$ fusion of the coregistered subtraction between ictal and interictal SPECT. For the ictal SPECT, when the tracer was injected (30 s after seizure onset), the patient was no longer reading. For the interictal (and not during reading). Axial, sagittal and coronal sections centred on the non-contiguous hyperperfused areas: (A) left occipito-parietal junction area, (B) left lateral temporal area (middle and inferior temporal gyri), (C) left inferior frontal area. SPECT, injection was performed at rest

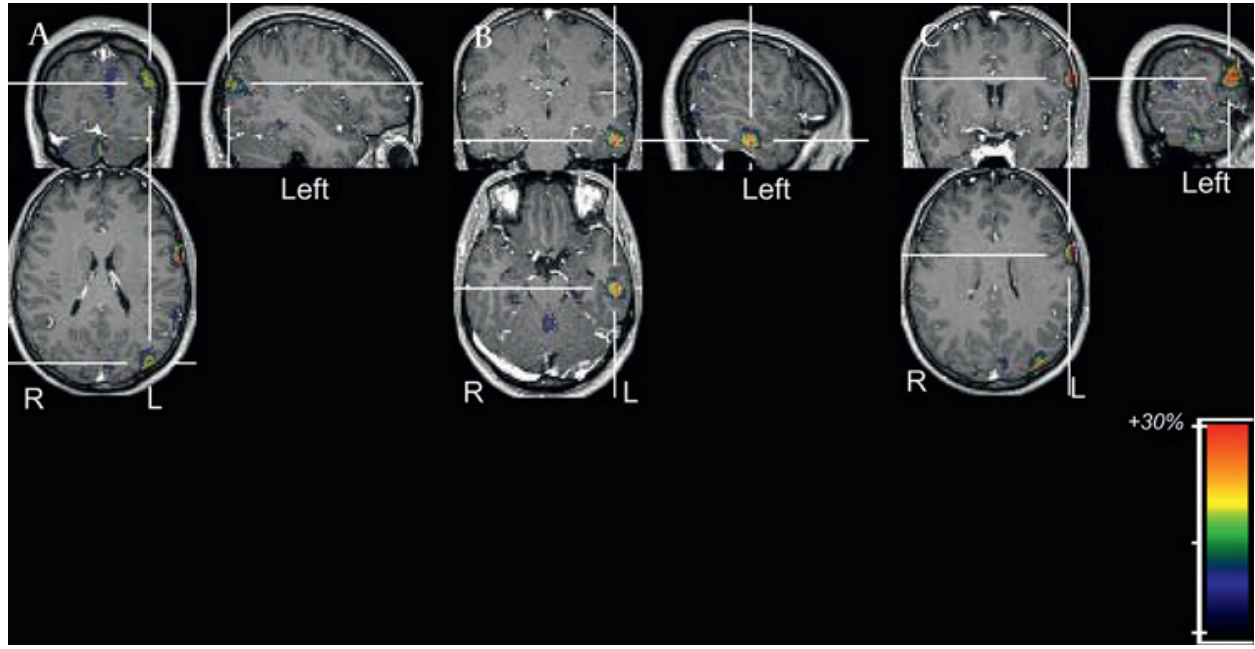

reports of reading epilepsies corresponding to posterior cortex epilepsies or epilepsies of the dominant temporo-occipital region thus exist. However, few precise anatomo-functional investigations were available in most of these reading epilepsy cases (particularly for those dating from 1956, 1957, 1966 and 1975). In the present case, initial ictal signs, paroxysmal a- or dyslexia associated with a palinopsia, were similar to those described previously. $^{12} 1619$ HR-EEG and PET revealed interictal abnormalities in the left temporo-occipital junction. Ictal video-EEG recording and ictal SPECT argued in favour of an initial left temporo-parieto-occipital junction implication with occipitotemporal predominance, propagating to more anterior areas of the left hemisphere. Ictal SPECT demonstrated a set of hyperperfused structures including the left occipito-parietal junction area, left lateral middle and inferior temporal gyri and a left middle frontal area.

The hyperperfused structures highlighted by the ictal SPECT are close to the anatomy of reading in normal subjects. Indeed, neuroimaging studies of reading raise the hypothesis of a gradual bilateral-to-left and posterior-to-anterior recruitment of reading related areas. ${ }^{25-31}$ Visual informations are initially processed by occipito-temporal areas and subsequently transferred to a localised region of the left occipito-temporal sulcus, just lateral to the fusiform gyrus, devoted to the function of identifying visual letter strings, the "visual word form area.'26 28 The posterior lateral temporo-parietal region appears to be associated with phonological and/or semantic word processing. ${ }^{25} 26$ Neuroimaging studies (PET and FMRI) reveal three main brain areas devoted to semantic processing. These areas that enable the access to the meaning of the words being read are the basal temporal language area, localised in the posterior part of the inferior temporal gyrus, in the prolongation of the occipitotemporal junction, the posterior middle temporal gyrus and the triangular part of the inferior frontal gyrus. ${ }^{27}$ In our observation, a hyperperfused area in the left frontal region was also highlighted by the ictal SPECT. This could correspond to a semantic area or to language production during the seizure (the patient verbally alerted nurses, commented upon subjective seizure symptoms and then presented an elementary vocalisation). According to data obtained in our patient, we can infer that, in

Table 1 Comparison of the two variants of reading epilepsies, according to the literature and the case reported: jaw jerk variant and the posterior variant, characterised by visual symptoms and a- or dyslexia

\begin{tabular}{|c|c|c|}
\hline & Reading epilepsy jaw jerk variant & Reading epilepsy posterior variant (visual symptoms, a- or dyslexia) \\
\hline Triggers other than reading & Writing, talking, thinking, ${ }^{1}$ chess playing ${ }^{11}$ & Playing cards ${ }^{13}$ \\
\hline Unprovoked seizures & Yes $^{111}$ & Yes $^{1}: 5 \%{ }^{12} ;$ no $^{13} 16$ \\
\hline Ictal symptomatology & Jaw jerks & $\begin{array}{l}\text { Elementary visual hallucination, visual illusion, blurred vision, } \\
\text { palinopsia, alexia, dyslexia }{ }^{1} 11-1319\end{array}$ \\
\hline Age (years) at onset & $12-46^{111} 14$ & $8-28^{112}$ \\
\hline Family history & Yes in $25 \%^{1}$ & No, ${ }^{116}$ undefined $^{12} 1319$ \\
\hline Length of seizures & Brief: few seconds ${ }^{11}$ & More prolonged: $50 \mathrm{~s}$ to $2 \min ^{1} 1219$ \\
\hline Interictal EEG & $\begin{array}{l}\text { Usually normal, }{ }^{817} \text { paroxysmal discharges maximal in the occipital and } \\
\text { parietal areas }\end{array}$ & $\begin{array}{l}\text { L posterior interictal spikes, }{ }^{12} \text { bilateral parietal and frontal } \\
\text { abnormalities }^{13}\end{array}$ \\
\hline Ictal EEG & $\begin{array}{l}\text { 'generalised' spikes-and-waves, }{ }^{11}{ }^{14} \mathrm{~L} \text { temporo-parietal sharp- } \\
\text { waves, }^{6} 814 \mathrm{~L} \text { fronto-central spikes, }{ }^{4} \mathrm{R} \text { fronto-temporal spikes }{ }^{14}{ }^{17}\end{array}$ & L occipito-temporal rhythmic discharge ${ }^{12}$ \\
\hline Ventriculography & - & L occipital atrophy ${ }^{12}$ \\
\hline IRM & Normal, encephalomalacia in the $L$ frontal lobe ${ }^{4}$ in symptomatic forms & Normal, arachnoid cyst at the $L$ temporal pole ${ }^{1}$ \\
\hline${ }^{18} \mathrm{~F}-\mathrm{FDG}-\mathrm{PET}$ & - & L occipito-temporal hypometabolism \\
\hline${ }^{11} \mathrm{C}$-DPN-PET & $\begin{array}{l}\text { Decrease bilateral temporal and } L \text { frontal, }{ }^{35} \text { decrease } L \text { temporo- } \\
\text { parieto-occipital junction }{ }^{18}\end{array}$ & - \\
\hline Ictal SPECT & Hyperperfusion bilateral frontal and $L$ temporal ${ }^{33}$ & $\begin{array}{l}\mathrm{L} \text { occipito-parietal junction area, } \mathrm{L} \text { lateral middle and inferior temporal } \\
\text { gyri, } \mathrm{L} \text { inferior frontal area }\end{array}$ \\
\hline Spike triggered fMRI & $L$ frontal cortex, ${ }^{36} L$ motor and premotor areas ${ }^{37}$ & - \\
\hline HR-EEG & - & L occipito-temporal junction \\
\hline Therapeutic response & CZP; CLB; VPA, ${ }^{1} 1436 \mathrm{PHT}^{24}$ & $\mathrm{CBZ}^{1} ; \mathrm{PB}^{12} ; \mathrm{PHT}, \mathrm{PB}^{13} ; \mathrm{VPA}^{16}$ \\
\hline Physiopathology/classification & Partial epilepsy, generalised epilepsy ${ }^{11}$ & Partial epilepsy \\
\hline
\end{tabular}

CBZ, carbamazepine; CLB, clobazam; CZP, clonazepam; L, left; PB, phenobarbitone; PHT, phenytoin; VPA, sodium valproate. 
this form of reading epilepsy, the pathophysiological process electively involves the brain network sustaining physiological reading. Moreover, ictal a- or dyslexia is very close to the effect of electrical stimulation of dominant occipito-temporal region. ${ }^{32}$ Indeed, it was recently demonstrated that electrical stimulation of the posterior fusiform and inferior temporal gyri of the dominant hemisphere produced alexia, reading difficulties involving sentences and words, sparing letter by letter reading.

There are few non-invasive functional studies concerning reading epilepsy in the literature, and they mainly focus on reading epilepsies clinically characterised by jaw jerks. One study using ictal SPECT reports focal hyperperfusion in both frontal lobes and in the left temporal area (one right-handed patient). ${ }^{33}$ In another study, ictal SPECT showed hyperperfusion of the right temporal lobe (one right-handed patient with also a history of non-reading-related seizures affecting the left leg). ${ }^{34}$ Using $\left[{ }^{11} \mathrm{C}\right]$ diprenorphine (DPN)-PET, dynamic ictal scans of opioid receptors have been carried out in reading epilepsy patients. One reading-epilepsy patient (jaw jerks) showed periictal opioid binding decreases in both temporal lobes and the left frontal lobe. ${ }^{35}$ In another study comparing five reading-epilepsy patients (jaw jerks) with controls, mean $\left[{ }^{11} \mathrm{C}\right]-\mathrm{DPN}$ binding to opioid receptors was significantly lower in the left parietotemporo-occipital cortex. $\left[{ }^{11} \mathrm{C}\right]-\mathrm{DPN}$ studies suggest that opioidlike substances are involved in the termination of reading seizures. ${ }^{18}$ Interestingly, in spite of distinct ictal semiology (jaw jerks vs a- or dyslexia and visual symptoms), DPN-PET findings are close to our case ictal SPECT subtraction. These results suggest a common basis for the pathophysiology of reading epilepsy, whether characterised clinically by alexia/dyslexia or jaw jerks, with implication of the posterior part of reading related areas. However, using spike-triggered fMRI, two studies investigating reading epilepsy patients (jaw jerks) highlighted more anterior areas in the left hemisphere. In the first study (two patients), the activation pattern was localised in the left middle frontal gyrus. ${ }^{36}$ In the second study, reading-induced seizures occurred in six of nine patients. Activation patterns were observed within left motor and premotor areas, left striatum, mesiotemporal areas, ventral frontal cortex and thalamus. $^{37}$

Reading epilepsy is a distinct form of reflex epilepsy, classified among idiopathic, age- and localisation-related (partial) epilepsies. ${ }^{17}$ Clinical expression is age-related, with an onset most often in the second and third decades. ${ }^{1}$ The condition is nonprogressive. All or almost all seizures are precipitated by the act of reading. As previously analysed, ${ }^{1}$ it appears that reading epilepsy has a large clinical spectrum, with a most frequent variant clinically characterised by jaw jerks and a rare variant characterised by initial visual symptoms and a- or dyslexia (posterior variant). In both subtypes, seizures usually evolve into generalised seizure if reading persists. Analysing the literature, we observed that despite reading as the same triggering stimulus, these two variants of reading epilepsy differ in terms of ictal semiology, length of seizures, interictal and ictal EEG characteristics, results of other functional non-invasive studies, physiopathology and response to antiepileptic treatment. We have summarised these characteristics of the two reading epilepsy variants in table 1 .

In the jaw jerk variant, ictal EEG is characterised either by brief, bilateral, synchronous spikes and waves or by focal ictal modifications. ${ }^{1} 468111417$ In the posterior variant, ictal EEG is characterised by a left occipito-temporal rhythmic discharge as in our case. ${ }^{1}{ }^{12}$ For both variants, some functional neuroimaging studies are suggestive of left posterior cortex involvement, corresponding to the posterior part of the neural network that underlies the function of reading. ${ }^{18}$ Other neuroimaging studies suggest a more anterior/motor origin for reading epilepsy characterised by jaw jerks. ${ }^{33}$ 35-37 Reading epilepsy patients (jaw jerk variant) are usually best controlled by clonazepam or sodium valproate, whereas those with the posterior variant respond to antiepileptic drugs that are effective for partial seizures, such as carbamazepine. ${ }^{1}$

In conclusion, the case we report reveals features characteristic of primary reading epilepsy: family history of epilepsy; onset in the third decade; seizures exclusively provoked by reading meaningful material; favourable response to antiepileptic treatment; and clinical and paraclinical characteristics of the reading epilepsy posterior variant. According to these criteria, we thus consider that the case we report belongs to this idiopathic epilepsy syndrome.

Acknowledgements We thank A McGonigal, for the revision of the English version, and S Dufau, for reading the manuscript.

\section{Competing interests None.}

Patient consent Obtained.

Ethics approval Ethics approval was provided by the institutional review board of the French Institute of Heath (IRB0000388, FWA00005831).

Provenance and peer review Not commissioned; externally peer reviewed.

\section{REFERENCES}

1. Koutroumanidis $\mathbf{M}$, Koepp MJ, Richardson MP, et al. The variants of reading epilepsy. A clinical and video-EEG study of 17 patients with reading-induced seizures. Brain 1998:121(Pt 8):1409-27.

2. Bickford RG, Whelan JL, Klass DW, et al. Reading epilepsy: clinical and electroencephalographic studies of a new syndrome. Trans Am Neurol Assoc 1956;81:100-2.

3. Lee SI, Sutherling WW, Persing JA, et al. Language-induced seizure. A case of cortical origin. Arch Neurol 1980;37:433-6.

4. Ritaccio AL, Hickling EJ, Ramani V. The role of dominant premotor cortex and grapheme to phoneme transformation in reading epilepsy. A neuroanatomic, neurophysiologic, and neuropsychological study. Arch Neurol 1992;49:933-9.

5. Bartolomei F, Farnarier G, Elias Z, et al. Facial reflex myoclonus induced by language: a neuropsychological and neurophysiological study. Neurophysiol Clin 1999;29:263-70.

6. Ramani V. Reading epilepsy. Adv Neurol 1998;75:241-62

7. Engel J Jr; International League Against Epilepsy (ILAE). A proposed diagnostic scheme for people with epileptic seizures and with epilepsy: report of the ILAE Task Force on Classification and Terminology. Epilepsia 2001;42:796-803.

8. Panayotopoulos CP. Reflex seizures and reflex epilepsies. In: Nadine Lemmens, ed A clinical guide to epileptic syndromes and their treatment. 2nd edn. Springer, 2008:437-71.

9. Stevens H. Reading epilepsy. N Engl J Med 1957;257:165-70.

10. Singh B, Anderson L, al Gashlan M, et al. Reading-induced absence seizures. Neurology 1995:45:1623-4.

11. Radhakrishnan K, Silbert PL, Klass DW. Reading epilepsy. An appraisal of 20 patients diagnosed at the Mayo Clinic, Rochester, Minnesota, between 1949 and 1989, and delineation of the epileptic syndrome. Brain 1995;118:75-89.

12. Chavany JA, Fischgold H, Messimy $R$, et al. Clinical and EEG aspects of a case of epilepsy electively induced by reading. Rev Neurol 1956;95:381-7.

13. Bingel A. Reading epilepsy. Neurology 1957:7:752-6.

14. Saenz-Lope E, Herranz-Tanarro FJ, Masdeu JC. Primary reading epilepsy. Epilepsia 1985;26:649-56.

15. Wolf P. Reading epilepsy. In: Roger J, Bureau M, Dravet C, et al, eds. Epileptic syndromes in infancy, childhood and adolescence. 2nd edn. Montrouge: John Libbey Eurotext Ltd, 1992:281-98.

16. de Weerdt CJ, Van Rijn AJ. Conditioning therapy in reading epilepsy. Electroencephalogr Clin Neurophysiol 1975;39:417-20.

17. Wolf $\mathbf{P}$, Inoué $Y$. Complex reflex epilepsies: reading epilepsy and praxis induction. In Roger J, Bureau M, Dravet C, et al, eds. Epileptic syndromes in infancy, childhood and adolescence. 4th edn. Montrouge: John Libbey Eurotext Ltd, 2005:347-58.

18. Koepp MJ, Richardson MP, Brooks DJ, et al. Focal cortical release of endogenous opioids during reading-induced seizures. Lancet 1998;352:952-5.

19. Gastaut H, Tassinari CA. Triggering mechanisms in epilepsy. The electroclinical point of view. Epilepsia 1966:7:85-138.

20. Pegna AJ, Picard F, Martory MD, et al. Semantically-triggered reading epilepsy: an experimental case study. Cortex 1999;35:101-11.

21. Scherg M. Functional imaging and localisation of electromagnetic brain activity. Brain Topogr 1992;5:103-11. 
22. Mosher JC, Lewis PS, Leahy RM. Multiple dipole modeling and localization from spatio-temporal MEG data. IEEE Trans Biomed Eng 1992;39:541-57.

23. Gavaret M, Trebuchon A, Bartolomei F, et al. Source localization of scalp-EEG interictal spikes in posterior cortex epilepsies investigated by HR-EEG and SEEG. Epilepsia 2009;50:276-89.

24. Kartsounis LD. Comprehension as the effective trigger in a case of primary reading epilepsy. J Neurol Neurosurg Psychiatry 1988;51:128-30.

25. Price CJ, Wise RJ, Watson JD, et al. Brain activity during reading. The effects of exposure duration and task. Brain 1994:117:1255-69.

26. Cohen L, Dehaene S, Naccache L, et al. The visual word form area: spatial and temporal characterization of an initial stage of reading in normal subjects and posterior split-brain patients. Brain 2000;123:291-307.

27. Jobard G, Crivello F, Tzourio-Mazoyer N. Evaluation of the dual route theory of reading: a metanalysis of 35 neuroimaging studies. Neuroimage 2003;20:693-712.

28. Dehaene S, Cohen L, Sigman M, et al. The neural code for written words: a proposal. Trends Cogn Sci 2005;9:335-41.

29. Dhond RP, Witzel T, Dale AM, et al. Spatiotemporal cortical dynamics underlying abstract and concrete word reading. Hum Brain Mapp 2007:28:355-62.
30. Levy J, Pernet C, Treserras S, et al. Piecemeal recruitment of left-lateralized brain areas during reading: a spatio-functional account. Neuroimage 2008;43:581-91.

31. Simos PG, Pugh K, Mencl E, et al. Temporal course of word recognition in skilled readers: A magnetoencephalography study. Behav Brain Res 2009;197:45-54.

32. Mani J, Diehl B, Piao Z, et al. Evidence for a basal temporal visual language center cortical stimulation producing pure alexia. Neurology 2008:71:1621-7.

33. Miyamoto A, Takahashi S, Tokumitsu A, et al. Ictal HMPAO-single photon emission computed tomography findings in reading epilepsy in a Japanese boy. Epilepsia 1995:36:1161-3

34. Kücük NO, Yigit A, lbis E, et al. Functional imaging in reading epilepsy: a case report. Ann Nucl Med 1999;13:355-6.

35. Koepp MJ, Hansen ML, Pressler RM, et al. Comparison of EEG, MRI and PET in reading epilepsy: a case report. Epilepsy Res 1998;29:251-7.

36. Archer JS, Briellmann RS, Syngeniotis A, et al. Spike-triggered fMRI in reading epilepsy: involvement of left frontal cortex working memory area. Neurology 2003;60:415-21

37. Salek-Haddadi A, Mayer T, Hamandi K, et al. Imaging seizure activity: A combined EEG/EMG-fMRI study in reading epilepsy. Epilepsia 2009;50:256-64. 